\title{
MDR1-P-glycoprotein behaves as an oncofetal protein that promotes cell survival in gastric cancer cells
}

\author{
Alba Rocco ${ }^{1, *}$, Debora Compare ${ }^{1, *}$, Eleonora Liguori ${ }^{1}$, Alessandra Cianflone ${ }^{1}$, Giuseppe Pirozzi ${ }^{2}$, Virginia Tirino ${ }^{2}$, \\ Alessandra Bertoni ${ }^{3}$, Margherita Santoriello ${ }^{3}$, Corrado Garbi ${ }^{3}$, Maria D'Armiento ${ }^{4}$, Stefania Staibano ${ }^{4}$ and \\ Gerardo Nardone ${ }^{1}$
}

P-glycoprotein (P-gp), traditionally linked to cancer poor prognosis and multidrug resistance, is undetectable in normal gastric mucosa and overexpressed in gastric cancer (GC). We propose that P-gp may be involved in Helicobacter pylori $(H p)$-related gastric carcinogenesis by inhibiting apoptosis. Aim of the study was to evaluate the expression of P-gp in fetal stomach and in Hp-related gastric carcinogenesis, the epigenetic control of the multi-drug resistance-1 (MDR1) gene, the localization and interaction between $\mathrm{P}-\mathrm{gp}$ and $\mathrm{Bcl}-\mathrm{x}_{\mathrm{L}}$ and the effect of the selective silencing of $\mathrm{P}-\mathrm{gp}$ on cell survival. $\mathrm{P}$-gp and $\mathrm{BCl}-\mathrm{xl}$ expression was evaluated by immunohistochemistry on 28 spontaneously abortive human fetuses, 66 $\mathrm{Hp}$-negative subjects, $138 \mathrm{Hp}$-positive chronic gastritis (CG) of whom 28 with intestinal metaplasia (IM) and 45 intestinal type GCs. P-gp/Bcl- $x_{\mathrm{L}}$ colocalization was investigated by confocal immunofluorescence microscopy and protein-protein interaction by co-immunoprecipitation, in basal conditions and after stress-induced apoptosis, in GC cell lines AGS and MKN-28 and hepatocellular carcinoma cell line Hep-G2. The role of P-gp in controlling apoptosis was evaluated by knocking down its expression with a specific small interfering RNAs in stressed AGS and MKN-28 cell lines. P-gp is expressed in the gastric mucosa of all human fetuses while, it is undetectable in adult normal mucosa and re-expressed in 30/110 Hp-positive non-IM-CG, 28/28 IM-CG and 40/45 GCs. P-gp expression directly correlates with that of Bcl- $\mathrm{x}_{\mathrm{L}}$ and with the promoter hypomethylation of the MDR1 gene. In GC cell lines, P-gp is localized on the plasma membrane and mitochondria where it colocalizes with $\mathrm{Bcl}-\mathrm{x}_{\mathrm{L}}$. Co-immunoprecipitation confirms the physical interaction between P-gp and $\mathrm{BCl}-\mathrm{x}_{\mathrm{L}}$ in AGS, MKN-28 and Hep-G2, at both basal level and after stress-induced apoptosis. The selective silencing of P-gp sensitizes GC cells to stress-induced apoptosis. P-gp behaves as an oncofetal protein that, by cross-talking with $\mathrm{BCl}-\mathrm{x}_{\mathrm{L}}$, acts as an anti-apoptotic agent in $\mathrm{Hp}$-related gastric carcinogenesis.

Laboratory Investigation (2012) 92, 1407-1418; doi:10.1038/labinvest.2012.100; published online 2 July 2012

KEYWORDS: apoptosis; gastric carcinogenesis; H. pylori; P-glycoprotein; stomach morphogenesis

P-glycoprotein (P-gp), the main product of the multi-drug resistance-1 (MDR1) gene, is a membrane-associated glycoprotein, normally expressed on the apical membrane of various cell types, ${ }^{1}$ where it extrudes drugs and other toxic agents by acting as an energy-dependent efflux pump. ${ }^{2} \mathrm{P}$-gp has been related to the intrinsic and acquired drug resistance in several neoplasms and represents one of the leading cause of the failure of chemotherapeutic treatments and poor prognosis of cancer. ${ }^{3,4}$ In the gastrointestinal tract, under physiological conditions, P-gp expression progressively decreases from ileum, where it shows the maximum level of expression, to the stomach where it is absent. ${ }^{5}$ In contrast, P-gp is generally overexpressed in gastric cancer (GC), where it has been traditionally linked to poor prognosis and multidrug resistance. ${ }^{6,7}$

In a previous study, we found P-gp expressed in a subset of chronic gastritis (CG) patients directly related to the severity of the inflammatory state of gastric mucosa and Helicobacter pylori (Hp) infection. ${ }^{8}$ More interestingly, P-gp was expressed in both metaplastic and non-metaplastic areas of gastric

\footnotetext{
${ }^{1}$ Department of Clinical and Experimental Medicine, Gastroenterology Unit, 'Federico II' University of Naples, Naples, Italy; ${ }^{2}$ Department of Experimental Oncology, National Cancer Institute, Naples, Italy; ${ }^{3}$ Department of Cellular and Molecular Biology and Pathology, 'Federico II' University of Naples, Naples, Italy and ${ }^{4}$ Department of Biomorphological and Functional Science, Pathology Unit, 'Federico II' University of Naples, Naples, Italy

Correspondence: Professor G Nardone, MD, Department of Clinical and Experimental Medicine, Gastroenterology Unit, Federico II University of Naples, via Pansini 5, 80131 Naples, Italy.

*These authors equally contributed to the work.

Received 6 December 2011; revised 14 May 2012; accepted 14 May 2012
} 
mucosa and directly related to $\mathrm{Bcl}-\mathrm{x}_{\mathrm{L}}$, a well-known antiapoptotic agent. ${ }^{9}$ Based on these observations, it seems conceivable to postulate that P-gp could mean other than 'multidrug resistance' and have a more general function in gastric mucosa. Some reports suggest that P-gp may act as a primary anti-apoptotic agent by reducing the pool of plasma membrane phospholipids or by inhibiting caspase-mediated apoptosis. $^{10,11}$ In leukemia and many types of cancers, including hepatocellular, colorectal and prostate cancer, P-gp has been demonstrated to promote cell survival. ${ }^{12-15}$ Until now, no data are available on the possible anti-apoptotic role of P-gp in gastric carcinogenesis.

It is universally accepted that the molecular pathways that underlie normal organogenesis are similar to those perturbed during carcinogenesis. Apoptosis or programmed cell death is crucial for both organogenesis and carcinogenesis. A coordinated regulation of apoptosis, indeed, is critical for the appropriate architectural development of organs and tissues, ${ }^{16}$ whereas the inhibition of cell death represents one of the fundamental hallmarks of carcinogenesis. ${ }^{17}$

In this study, we evaluate the expression of P-gp in human fetal stomach and in $\mathrm{Hp}$-related gastric carcinogenesis, its implication in controlling apoptosis by interacting with $\mathrm{Bcl}-\mathrm{x}_{\mathrm{L}}$ and the effect of the selective silencing of P-gp on cell survival in an in vitro model.

\section{MATERIALS AND METHODS 'Ex Vivo' Study \\ Population and tissue sampling}

Gastric tissue specimens were obtained from 28 abortive fetuses (18 male and 10 female), 204 consecutive subjects (132 men and 72 women; age range: $20-73$ years) recruited between those referred to our Endoscopy Unit on account of dyspepsia and 45 patients ( 27 men and 18 women; age range 48-75 years) undergoing gastric surgery for primary intestinal type GC. Gastric mucosa samples from human fetuses were obtained from spontaneously abortive human fetuses.

In dyspeptic patients and in patients with GC, mucosa specimens were obtained at the time of upper gastrointestinal endoscopy and surgery, respectively. $H p$ infection was diagnosed by concordance between histology and rapid urease test. Dyspeptic patients with $H p$-related gastric diseases were also examined by upper endoscopy at least 12 months after eradication therapy ( 7 days of treatment with omeprazole $20 \mathrm{mg}$ twice a day, clarithromycin $500 \mathrm{mg}$ twice a day and amoxocyllin $1000 \mathrm{mg}$ twice a day).

In all cases, tissue samples were stored at $-80{ }^{\circ} \mathrm{C}$ or fixed in buffered formalin for molecular, morphological and immunohistochemical examinations.

The study was performed in accordance with the guidelines of the Institutional Ethics Committee of Federico II University of Naples. Informed consent for the use of personal data and tissues was obtained from all patients and from parents of the human fetuses.

\section{Histopathological diagnosis}

The histopathological diagnosis was made on hematoxylin and eosin-stained sections; the modified Giemsa stain was used for $H p$ identification. In each biopsy sample, the presence of $H p$, degree of inflammation, glandular atrophy and IM was evaluated and classified according to the updated Sydney system. ${ }^{18}$ IM and GC were classified according to Jass and Filipe ${ }^{19}$ and Lauren, ${ }^{20}$ respectively.

\section{Immunohistochemistry}

For each biopsy, 4-lm thick serial sections were cut from paraffin blocks, mounted on acid-cleaned glass slides and heated at $55^{\circ} \mathrm{C}$ for $60 \mathrm{~min}$. Slides were de-waxed and rehydrated, then endogenous peroxidase activity was inhibited by incubation with $3 \% \mathrm{H}_{2} \mathrm{O}_{2}$ in methanol (20 min at room temperature). To reduce nonspecific background staining, slides were incubated with 5\% goat serum (15 min at room temperature). Finally, slides were incubated with the appropriate primary antisera in a moist chamber overnight at $4{ }^{\circ} \mathrm{C}$. Anti-MDR1-glycoprotein $\mathrm{p}$ (Biogenex, San Ramon, CA, USA, dilution 1:150) and anti-Bcl- $\mathrm{x}_{\mathrm{L}}$ (Santa Cruz Biotechnology, Santa Cruz, CA, USA, dilution 1:100) were used for P-gp and Bcl- $\mathrm{x}_{\mathrm{L}}$ detection, respectively. The avidin-biotin peroxidase complex procedure $(\mathrm{ABC}$ standard, Vector Laboratories, Burlingame, CA, USA) was then performed. Peroxidase activity was detected with diaminobenzidine as the substrate. Finally, sections were weakly counterstained with Harris's hematoxylin and mounted. Two independent approaches were used to confirm the specificity of the immunohistochemical signal: serial dilution of the primary antibody until the signal disappeared; and the use of nonimmune rabbit IgG or non-immune mouse $\operatorname{IgG}$ instead of primary antibody, which failed to reveal relevant staining.

The intensity of the staining of both P-gp and Bcl- $\mathrm{x}_{\mathrm{L}}$ was estimated on a scale from 0 (absent) to 4 (strong) and the area of positivity was assessed by providing values of 1 (focal or $<10 \%), 2(10-30 \%), 3(30-50 \%)$ or $4(>50 \%)$. The histological and immunohistochemical evaluations were performed on all biopsy samples, independently by two pathologists (SS and MDA). Following the independent reviews, each case was evaluated jointly and eventual disagreements were resolved by consensus.

\section{Analysis of MDR1 methylation status}

DNA was extracted from frozen samples using standard methods as described elsewhere. ${ }^{21}$ DNA modification for methylation specific polymerase chain reaction (PCR) was performed according to the manufacturer's instructions, using the CpGenome DNA Modification Kit (Millipore, Billerica, MA, USA). Primer sequences and amplification conditions were as described elsewhere. ${ }^{22,23}$ Briefly, DNA was extracted from gastric mucosa samples using standard phenolchloroform methods. After extraction, $2 \mu \mathrm{g}$ of DNA were used for bisulfite treatment. DNA was denatured in $0.2 \mathrm{~N}$ $\mathrm{NaOH}$ at $37^{\circ} \mathrm{C}$ for $10 \mathrm{~min}$ and incubated with $3 \mathrm{M}$ sodium 
bisulfite at $50^{\circ} \mathrm{C}$ for $16 \mathrm{~h}$. DNA was then purified using the Wizard cleanup system (Promega) and desulfonated with $0.3 \mathrm{~N} \mathrm{NaOH}$ at $25^{\circ} \mathrm{C}$ for $5 \mathrm{~min}$. DNA was then precipitated with ammonium acetate and ethanol, washed with $70 \%$ ethanol, dried and resuspended in $\mathrm{H}_{2} \mathrm{O}$. Primer pairs were specifically designed to amplify both methylated and unmethylated DNA, leading to PCR products of, 181 and 205 bp, respectively. A sample of colon cancer tissue was used as positive control.

\section{Western blotting}

Gastric mucosa samples were homogenized in $2 \mathrm{ml}$ of icecold lysis buffer containing 2\% SDS, 5\% (v/w) mercaptoethanol, $10 \%(\mathrm{v} / \mathrm{w})$ glycerol and $62.5 \mathrm{mM}$ TRIS (pH 6.8), using a tissue grinder. Protein concentration was determined by a modified Bradford method (Biorad assay kit, Bio-Rad Laboratories, Segrate, Italy) using bovine serum albumin as standard. Equal amounts of total proteins $(10 \mu \mathrm{g})$ were loaded in 12\% SDS-PAGE and electro-blotted onto a nitrocellulose membrane. Nonspecific binding was blocked with 5\% non-fat milk in PBS for $1 \mathrm{~h}$ at room temperature. The membrane was then incubated with anti-MDR1-P-gp antibody (Biogenex, dilution 1:500) overnight at $4{ }^{\circ} \mathrm{C}$, rinsed for three times with TBST, followed by incubation with HRPlabeled goat anti-mouse IgG for $1 \mathrm{~h}$. After washing three times with TBST, the bands were developed with the enhanced chemiluminescence (ECL) reagent for $5 \mathrm{~min}$. Chemiluminescent signals were quantified by scanning densitometry (Amersham Biosciences, Piscataway, NJ, USA).

\section{'In Vitro' Study \\ Cell lines}

Human gastric adenocarcinoma cell lines AGS and MKN-28, and human hepatocarcinoma cell line Hep-G2, purchased from ATCC (American Type Culture Collection, Manassas, VA, USA), were used to carry out in vitro experiments. AGS and MKN-28 were cultured in RPMI 1640, whereas Hep-G2 cells were cultured in DMEM medium. Both medium culture were supplemented with 10\% FBS (Lonza, Basel, Switzerland), $100 \mathrm{units} / \mathrm{ml}$ penicillin and $100 \mu \mathrm{g} / \mathrm{ml}$ streptomycin (Mediatech, Herndon, VA, USA) at $37^{\circ} \mathrm{C}$ in a humidified incubator containing $5 \% \mathrm{CO}_{2}$.

Colocalization of P-gp and $B C l-x_{L}$ in AGS and MKN-28 cell lines $\mathrm{P}$-gp and $\mathrm{Bcl}-\mathrm{x}_{\mathrm{L}}$ were colocalized in AGS and $\mathrm{MKN}-28$ cells by using double immunofluorescence method. Briefly, cells were plated onto glass coverslips and fixed for $15 \mathrm{~min}$ in freshly prepared paraformaldehyde (4\%). After being washed in $0.1 \mathrm{M}$ PBS, cells were processed for permeabilization and blocking of nonspecific binding sites by a treatment with $0.2 \%$ Triton X-100 in PBS (5 min) and $10 \%$ goat serum (blocking buffer). Subsequently, cells were exposed overnight at $4{ }^{\circ} \mathrm{C}$ to mouse monoclonal anti-P-gp (Biogenex, dilution 1:250), rabbit polyclonal anti-Bcl- $\mathrm{x}_{\mathrm{L}}$ (Santa Cruz Biotechnology, dilution 1:250) primary antibodies, which were also diluted in the blocking buffer. After incubation, cells were rinsed in PBS $(3 \times 10 \mathrm{~min})$ and subsequently incubated at room temperature for $60 \mathrm{~min}$ with goat anti-mouse Alexa Fluor 488 (1:200; Molecular Probes) and goat anti-rabbit Alexa Fluor 546 (1:200; Molecular Probes) secondary antibodies, diluted in the blocking buffer. Appropriate negative controls were carried out omitting the primary antibodies. Finally, cells were rinsed in PBS $(3 \times 10 \mathrm{~min})$ and mounted in PBS-glycerol $(1: 1, \mathrm{vol} / \mathrm{vol})$. Fluorescence analysis was performed with the confocal laser scanner microscope Zeiss LSM 510.

To confirm the mitochondrial localization of P-gp, AGS and MKN-28 cells were stained with mouse monoclonal antiPgp antibody and MitoTracker Red (Molecular Probes, Invitrogen, Milan, Italy) a specific fluorescent probe for mitochondria. Briefly, cells were incubated in $300 \mathrm{nM}$ prewarmed medium solution of MitoTracker Red at $37^{\circ} \mathrm{C}$ for $45 \mathrm{~min}$, washed with fresh prewarmed medium, fixed and permeabilized. After immunostaining, coverslips were mounted on microscope slides using PBS/glycerol (1:1) mixture.

\section{Preparation of mitochondrial fraction}

Cells were washed twice with ice-cold PBS, and the pellet was suspended in $500 \mu \mathrm{l}$ of ice-cold buffer A (20 mM HEPES, pH 7.5, $1.5 \mathrm{mM} \mathrm{MgCl} 2,10 \mathrm{mM} \mathrm{KCl}, 1 \mathrm{mM}$ EDTA, $1 \mathrm{mM}$ EGTA, $1 \mathrm{mM}$ dithiothreitol, $0.1 \mathrm{mM}$ phenylmethylsulfonyl fluoride, and $10 \mu \mathrm{g} / \mathrm{ml}$ each leupeptin, aprotinin and pepstatin A) containing $250 \mathrm{mM}$ sucrose. To lyse the cells, the cell suspension was passed five times through a 26-gauge needle fitted to a syringe. Unbroken cells, large plasma membrane pieces, and nuclei were removed by centrifuging the homogenates at $1000 \mathrm{~g}$ at $4{ }^{\circ} \mathrm{C}$ for $10 \mathrm{~min}$. The resulting supernatant was subjected to $10000 \mathrm{~g}$ centrifugation at $4{ }^{\circ} \mathrm{C}$ for $20 \mathrm{~min}$. The pellet fraction (ie, mitochondria) was first washed with the above buffer A containing sucrose and then solubilized in $50 \mu \mathrm{l}$ of TNC buffer $(10 \mathrm{mM}$ Tris-acetate, $\mathrm{pH}$ 8.0, $0.5 \%$ Igepal CA-630, $5 \mathrm{mM} \mathrm{CaCl} 2)$. The supernatant was recentrifuged at $100000 \mathrm{~g}\left(4^{\circ} \mathrm{C}, 1 \mathrm{~h}\right)$ to generate cytosol.

\section{Western blot analysis of the cell fractions}

Cells were washed twice with PBS and then lysed by using lysis buffer (30 mM Tris-HCl pH 7.4, 1\% SDS). Cell lysates were centrifuged at $13000 \mathrm{~g}$, at $4{ }^{\circ} \mathrm{C}$, for $15 \mathrm{~min}$. The total cellular protein content was determined with $\mathrm{BCA}^{\mathrm{TM}}$ protein assay kit (Pierce, Rockford, IL, USA). Subsequently, cellular proteins were dissolved in sample loading buffer and run on $10 \%$ SDS-PAGE gels. Proteins were electrotransferred on PVDF membranes $(100 \mathrm{~V}, 1 \mathrm{~h})$. The membranes were rinsed with PBS and blocked with 10\% non-fat milk in PBS for $1 \mathrm{~h}$ at room temperature. Membranes were then incubated with the primary antibody anti-Pgp (Biogenex, dilution 1:200), and anti-Bcl- $\mathrm{x}_{\mathrm{L}}$ (Santa Cruz Biotechnology, dilution 1:1000), in $10 \%$ non-fat milk. After primary antibody incubation, membranes were rinsed in TBST wash buffer for $5 \mathrm{~min} \times 6$ 
times. Membranes were then incubated with the secondary antibody (HRP-conjugated goat anti-mouse and anti-rabbit IgG, 1:2500, Pierce) for $1 \mathrm{~h}$ at room temperature and rinsed in TBST wash buffer for $5 \mathrm{~min} \times 6$ times. The protein-antibody complexes were visualized by chemiluminescence (ECL system, Amersham Biosciences).

\section{Immunoprecipitation and immunoblot analysis}

Immunoprecipitation and immunoblot analysis were performed in AGS, MKN-28 and Hep-G2 cell lines in basal condition and in AGS cells also after overexpression of P-gp induced by oxidative stress (6-h incubation with $3 \% \mathrm{H}_{2} \mathrm{O}_{2}$ ). Briefly, cells were homogenized and sonicated in lysis buffer (20 mM Tris- $\mathrm{HCl}, \mathrm{pH}$ 7.4, $0.15 \mathrm{M} \mathrm{NaCl}, 10 \mathrm{mM}$ EDTA, 0.5\% Nonidet P-40) containing aprotinin $(5 \mu \mathrm{g} / \mathrm{ml})$, leupeptin $(10 \mu \mathrm{g} / \mathrm{ml})$, pepstatin $(2 \mu \mathrm{g} / \mathrm{ml}), 0.5 \mathrm{mM}$ phenylmethylsulfonyl fluoride, $2 \mathrm{mM}$ orthovanadate and $10 \mathrm{mM} \mathrm{NaF}$. The lysates were cleared by centrifugation at $14000 \mathrm{~g}$ for $15 \mathrm{~min}$. Cell lysates $(1 \mathrm{mg})$ were subjected to immunoprecipitation using anti-P-gp (Biogenex, $4 \mu \mathrm{g} / \mathrm{ml}$ ) and anti-Bcl- $\mathrm{x}_{\mathrm{L}}$ (Santa
Cruz Biotechnology, $4 \mu \mathrm{g} / \mathrm{ml}$ ) primary antibody, overnight at $4{ }^{\circ} \mathrm{C}$, then with protein A/G-Sepharose beads for $3 \mathrm{~h}$. Negative controls with nonspecific IgG were performed by adding mouse anti-IgG. Immune complexes were collected by centrifugation, washed three times with cold PBS and then eluted in lysis buffer. Eluted protein precipitates and samples of cells lysates $(100 \mu \mathrm{g})$ were separated on $10 \%$ SDS-PAGE. After being transferred to PROTRAN membrane, samples were immunoblotted with specific antibodies, then with horseradish peroxidase-conjugated secondary antibodies. Chemiluminescence (ECL) signal were quantified by scanning densitometry (ECL system, Amersham Biosciences).

\section{Transfection of small interfering RNA (siRNA) against MDR1} AGS and MKN-28 cells were seeded in six-well plates or in $60-\mathrm{mm}$ culture plates. After $48 \mathrm{~h}$, cells were transiently transfected, in serum-free medium, with Metafectene $\mathbb{R}$ Pro Transfection Reagent (Biontex Laboratories $\mathrm{GmbH}$ ) and $5 \mu \mathrm{M}$ siRNA solution in $1 \mathrm{X}$ siRNA buffer (Thermo Fisher
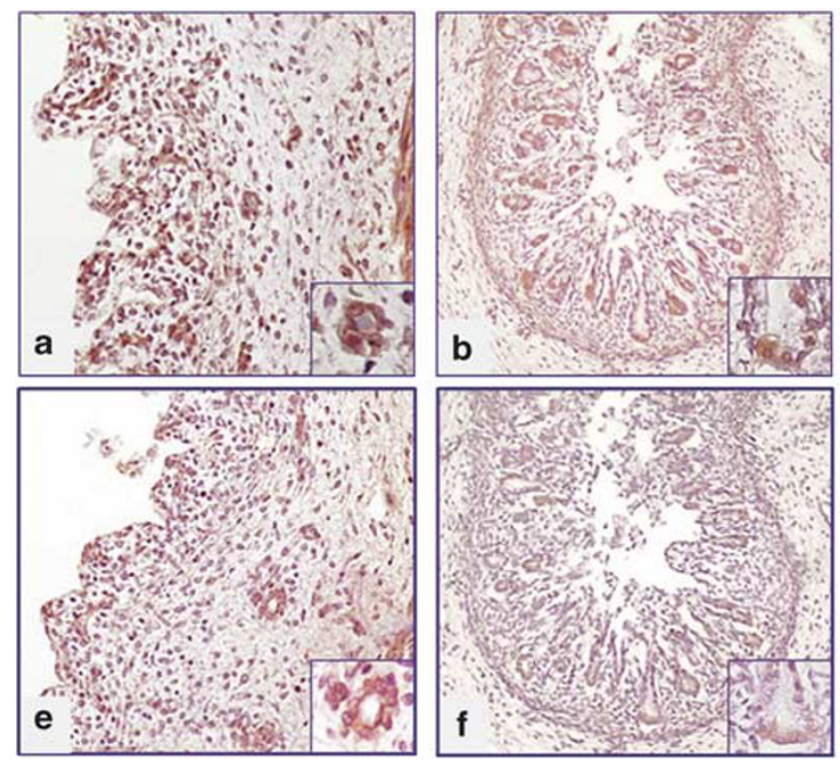
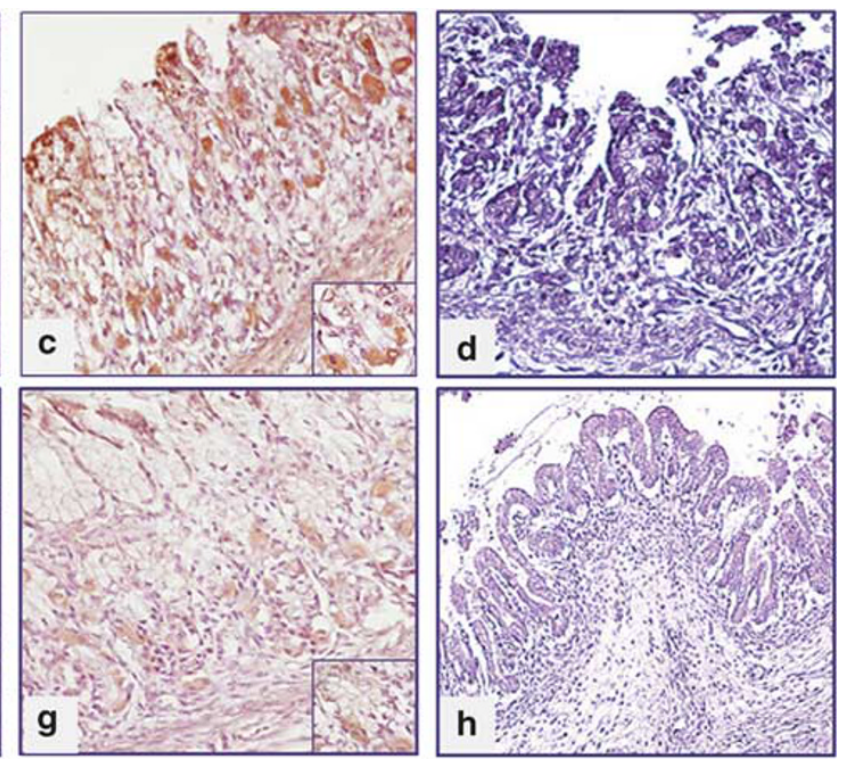

Figure 1 Immunohistochemical expression of P-gp and $\mathrm{BCl}-\mathrm{x}_{\mathrm{L}}$ in gastric mucosa of human fetuses. Top panel shows the representative immunopattern of P-gp in gastric mucosa at 20th week (a), 24th week (b) and 38th week of gestational age (c). Note the intense immunostaining in both superficial and glandular epithelium. Bottom panel shows Bcl- $x_{L}$ immunolocalization in gastric mucosa at 20th week (e), 24th week (f) and 38th week of gestational age (g). Note that the distribution of $\mathrm{BCl}-\mathrm{x}_{\mathrm{L}}$ in gastric epithelium is similar even if less intense of that of $\mathrm{P}$-gp (ABC technique, original magnification $\mathbf{b}$, $\mathbf{f} \times 100 ; \mathbf{a}, \mathbf{c}, \mathbf{e}, \mathbf{g} \times 200$; details $\times 400$ ). Negative controls $(\mathbf{d}, \mathbf{h})$ obtained by using nonimmune rabbit lgG instead of primary antibodies (original magnification d $\times 200, \mathbf{h} \times 100)$.

Figure 2 Immunohistochemical expression of $\mathrm{P}-\mathrm{gp}$ and $\mathrm{BCl}-\mathrm{x}_{\mathrm{L}}$ in adult gastric mucosa. Top panel shows the immunohistochemical localization of $\mathrm{P}$-gp in a case of $H p$-negative normal mucosa (a), Hp-positive non-metaplastic atrophic gastritis (b), Hp-positive metaplastic atrophic gastritis (c), intestinal type GC (d). Note the absence of the immunohistochemical signal in normal mucosa and the progressive increase in the intensity of immunostaining from $\mathrm{Hp}$ positive non-metaplastic atrophic gastritis to GC. Bottom panel shows Bcl- $x_{\mathrm{L}}$ immunolocalization in a case of $\mathrm{Hp}$-negative normal mucosa (f), $\mathrm{Hp}$-positive non-metaplastic atrophic gastritis (g), Hp-positive metaplastic atrophic gastritis (h) and intestinal type GC (i). Note that the cellular distribution of Bcl- $\mathrm{x}_{\mathrm{L}}$ parallels that of P-gp (ABC technique, original magnification $\mathbf{b}, \mathbf{c}, \mathbf{g} \times 100 ; \mathbf{d} \times 150 ; \mathbf{a}, \mathbf{f}, \mathbf{h}, \mathbf{i} \times 200$ ). Negative controls (e, j) obtained by using nonimmune rabbit IgG instead of primary antibodies (original magnification $\mathbf{d} \times 150, \mathbf{h} \times 200$ ). 

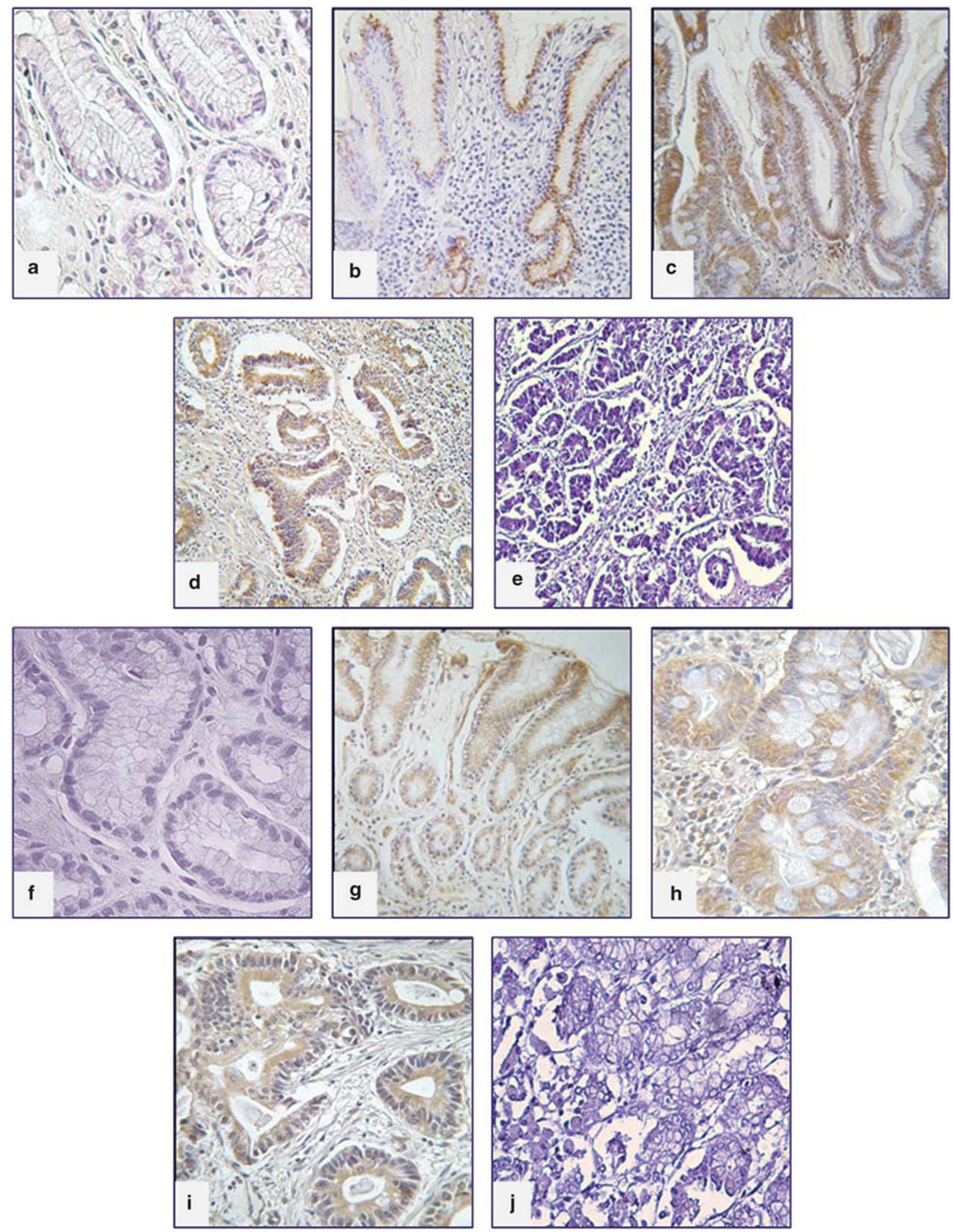
Scientific) in serum-free medium and incubated at $37^{\circ} \mathrm{C}$ in $5 \% \mathrm{CO}_{2}$ for $48 \mathrm{~h}$.

\section{Flow cytometry analysis}

After transfection, AGS and MKN 28 cells (control, scramble and siRNA transfected) were analyzed baseline and after 6-h incubation with $3 \% \mathrm{H}_{2} \mathrm{O}_{2}$. Cells were washed with binding buffer and suspended in $100 \mu \mathrm{l}$ Annexin V-binding buffer. Cells were then incubated with $5 \mu \mathrm{l}$ Annexin V-FITC and $5 \mu \mathrm{l}$ propidium iodide for $15 \mathrm{~min}$ at room temperature away from light before addition of $400 \mu \mathrm{l}$ Annexin V-binding buffer. The cell pellets were analyzed using a FACS Vantage flow cytometer (BD Biosciences, San Jose, CA, USA).

\section{Statistical analysis}

Data were analyzed using the SPSS package for Windows (version 17.0). The categorical variables were analyzed using the $\chi^{2}$ test or Fisher's exact test. The correlation between these variables was assessed using Spearman's correlation coefficient. Stepwise binary logistic regression was used to identify the association between the variables. $P$-values of 0.05 and 0.1 were selected as cutoff points to, respectively, enter and exit the stepwise procedure. Differences were considered to be significant at the $5 \%$ level.

\section{RESULTS}

\section{'Ex Vivo' Study}

$P$-gp and $B c l-x_{L}$ expression in gastric mucosa of human fetuses According to gestational age, 28 spontaneously abortive human fetuses were divided in three group: (i) 9 cases from 18th to 20th week; (ii) 15 cases from 21th to 36th week; and (iii) 4 cases from 37 th to 38 th week. In the gastric samples, P-gp was strongly expressed in the cytoplasm of all cells of both superficial and glandular epithelium with an

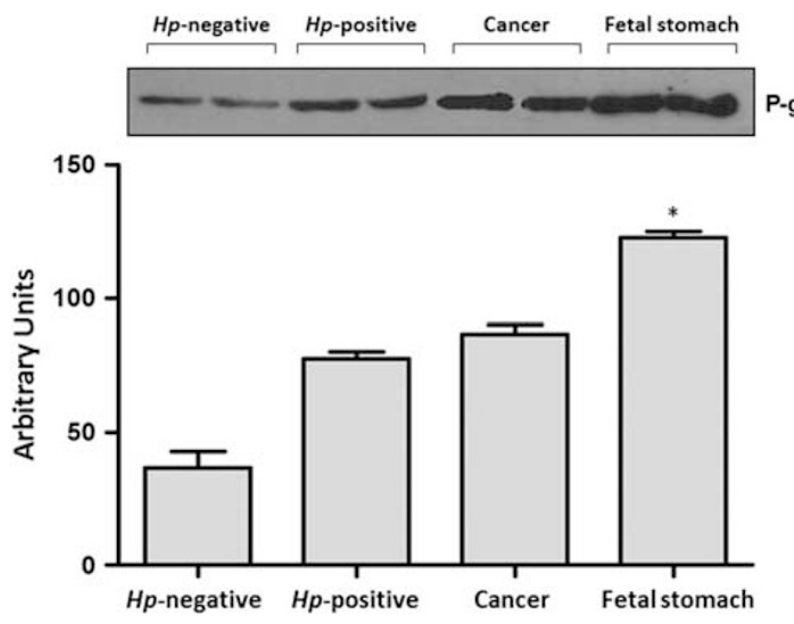

Figure 3 Expression of P-gp in gastric tissues by western blot analysis. A representative autoradiograph performed on tissue lysates of $\mathrm{Hp}$-negative subjects, $\mathrm{Hp}$-positive patients, GC patients and human fetuses. GAPDH expression was used as internal control. The histogram at bottom reports the mean densitometric values of P-gp/GAPDH ratio obtained from three independent experiments. ${ }^{\star}$ One-way ANOVA: $P<0.0001$. immunopositivity that paralleled the epithelial differentiation during stomach development (Figures $1 \mathrm{a}-\mathrm{c}$ ). The pattern of immunohistochemical expression of Bcl- $\mathrm{x}_{\mathrm{L}}$ was similar to that of P-gp being localized mainly in the cytoplasm of gastric epithelial cells (Figures 1e-g).

\section{$P$-gp and $B C l-x_{L}$ expression in Hp-related gastric carcinogenesis}

Patients with dyspeptic symptoms were classified according to endoscopic and histologic findings in $66 \mathrm{Hp}$-negative and $138 \mathrm{Hp}$-positive cases. In the $\mathrm{Hp}$-negative group, all subjects presented a normal gastric mucosa with minimal infiltration of lymphocytes and monocytes in the lamina propria. In the Hp-positive group, gastric atrophy was detected in $42 / 138$ cases; it was mild in 28, moderate in 10 and severe in 6 cases. Complete, type I IM, always associated with atrophy, was found in 28/138 cases.

In $H p$-negative gastric mucosa $\mathrm{P}$-gp protein was undetectable in all cases, whereas it was expressed in $27 \%$ (30/110) cases of $H p$-positive CG without IM and in $100 \%$ (28/28) of Hp-positive chronic atrophic gastritis with IM. In non-metaplastic CG, P-gp immunostaining ranged from mild-to-moderate and was distributed in the perinuclear area of the cytoplasm; conversely, in IM areas, P-gp showed an intense and diffuse cytoplasmic immunopositivity (Figures 2a-c).
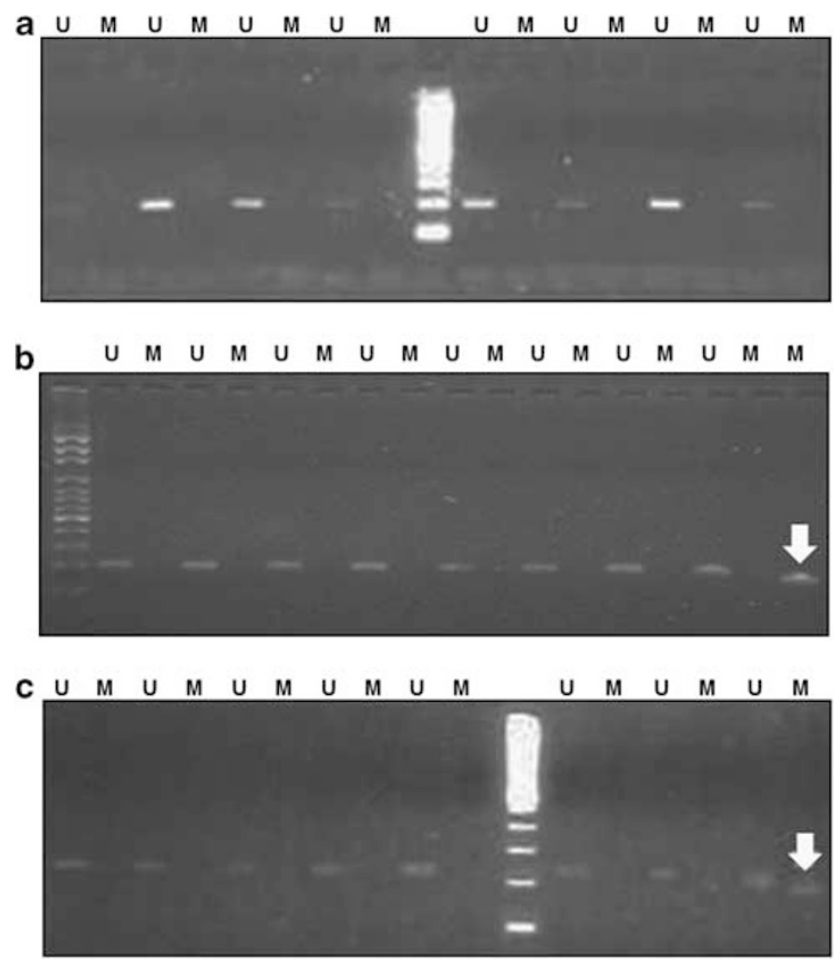

Figure 4 Methylation specific polymerase chain reaction results for MDR1 gene. DNA from: (a) fetal gastric mucosa, (b) gastritis biopsies and (c) GCs. Arrow in the panel $\mathbf{b}$ indicates the positive control from colon cancer tissue showing the presence of methylated promoter of P-gp-MDR1. Arrow in the panel $\mathbf{c}$ indicates the $\mathrm{GC}$ sample scored as methylated. $\mathrm{M}$, methylated; $\mathrm{U}$, unmethylated. 

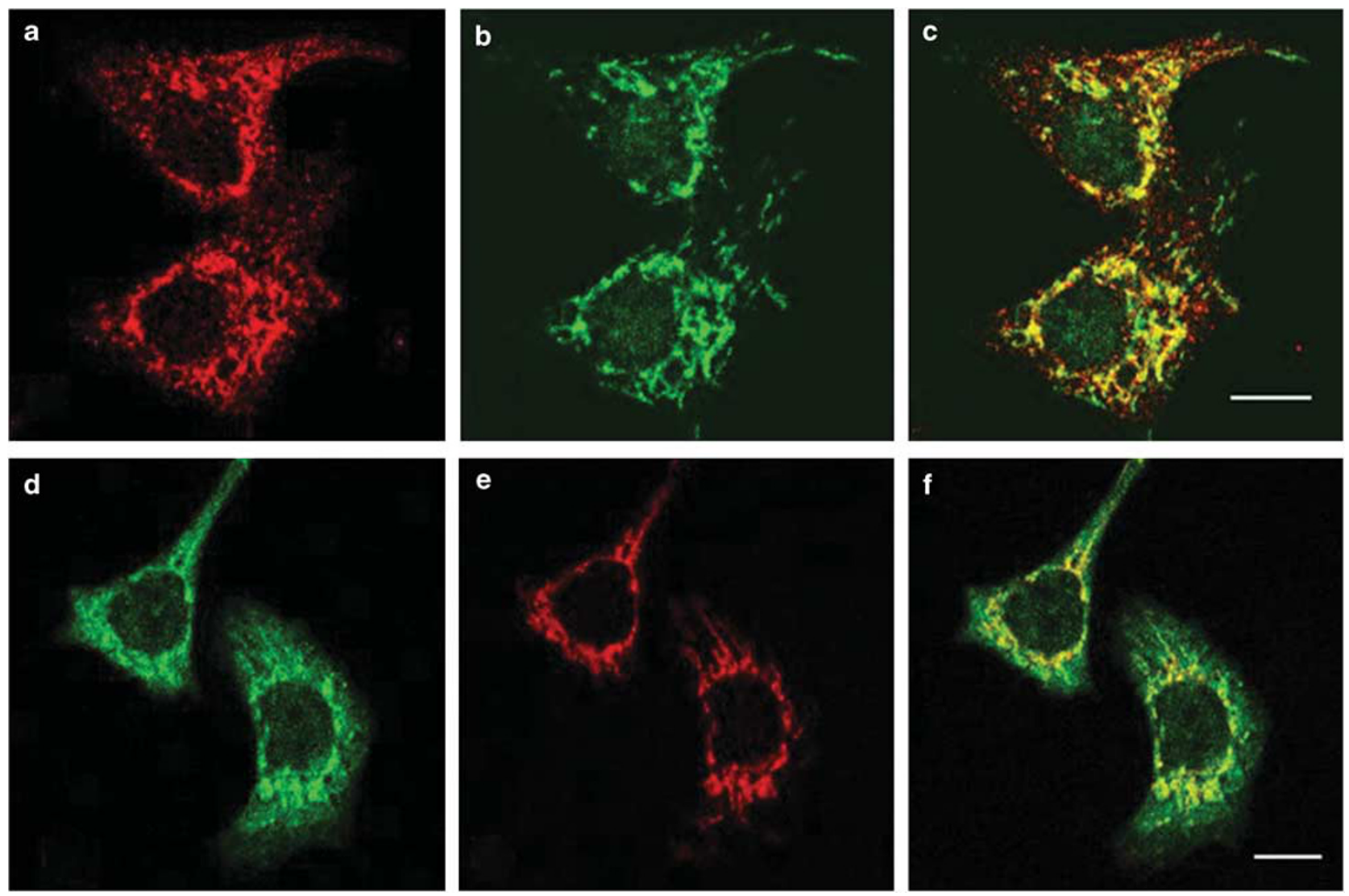

Figure 5 Immunofluorescence localization of P-gp and Bcl- $x_{L}$ in AGS cells. (a-c) Cells were double stained with anti-P-gp and anti-Bcl- $x_{L}$ antibodies. Both proteins stained a cytoplasmic membranous compartment. The merge evidenced a high degree of colocalization. (d-f) Cells were double stained with antiP-gp antibodies and the mitochondrion-selective probe MitoTracker Red. The merge in $f$ shows that P-gp staining superimposes with the MitoTracker staining. Bar $=15 \mu \mathrm{m}$. All the experiments were performed in triplicate.

By western blot analysis, the levels of P-gp were significantly higher in $H p$-positive than in $H p$-negative gastric mucosa $(P<0.05)$ (Figure 3).

$\mathrm{Bcl}-\mathrm{x}_{\mathrm{L}}$ was undetectable in gastric mucosa samples of $H p$-negative subjects (Figure 2f), and expressed in 20/110 (18\%) patients with $\mathrm{Hp}$-positive CG without IM and in 24/28 (86\%) of those with $\mathrm{Hp}$-positive CG associated with IM (Figures 2g, h).

By using Sperman's correlation, the levels of immunostaining of $\mathrm{P}$-gp were positively correlated with $H p$ infection $(P<0.05)$, atrophy $(P=0.02), \operatorname{IM}(P=0.001)$ and Bcl- $\mathrm{x}_{\mathrm{L}}(P=0.001)$ expression. However, when the data were analyzed by logistic regression, only $H p$ infection $(P<0.05)$ and $\mathrm{Bcl}-\mathrm{x}_{\mathrm{L}}$ expression $(P<0.01)$ were significantly associated with P-gp expression.

Of the 138 patients who underwent $H p$ eradication therapy, 28 dropped-out. In the remaining 110 patients, $H p$ infection was successfully eradicated in 88 cases. In this group of patients, Pg-p and Bcl- $\mathrm{x}_{\mathrm{L}}$ were overexpressed only in the presence of IM (16 subjects), whereas they were undetectable in the remaining 72 cases.
$P$-gp and $B C l-x_{L}$ expression in $G C$

Intestinal type GCs were 7 well, 26 moderately and 12 poorly differentiated. Twelve were confined to the mucosa or submucosa and 33 locally advanced. A strong P-gp immunostaining was found in $88 \%(40 / 45)$ of the cases, stronger than in CG and uniformly distributed in the cytoplasm of epithelial cells (Figure $2 \mathrm{~d}$ ). Bcl- $\mathrm{x}_{\mathrm{L}}$ expression was found in $75 \%(34 / 45)$ of the cases (Figure 2i).

By western blot analysis, the molecular expression of $\mathrm{P}$-gp was significantly higher in GC than $\mathrm{Hp}$-positive CG $(P<0.01)$.

In GC, the expression of P-gp significantly correlated with the high grade of differentiation $(r=0.50,95 \%$ CI: 0.66-0.28; $P<0.0001)$ and $\mathrm{Bcl}-\mathrm{x}_{\mathrm{L}}$ expression $(r=0.38,95 \%$ CI: $0.57-$ $0.15 ; P<0.001)$.

\section{Analysis of MDR1 methylation status}

The methylation status of P-gp-MDR1 gene was analyzed in 10 fetuses (gestational age 18th-20th week: 4 cases; 24 th-36th week: 4 cases; 38th week: 2 cases), $8 \mathrm{Hp}$-negative, 10 $H p$-positive and 8 intestinal type GCs. The P-gp-MDR1 
promoter region was unmethylated in the fetal mucosa, in CG and all GCs but one (Figure 4).

\section{'In Vitro' Study}

Localization of P-gp and Bcl- $x_{L}$ by confocal microscopy

In both AGS and MKN-28 cell lines, P-gp staining was localized mainly in the perinuclear region, at the level of
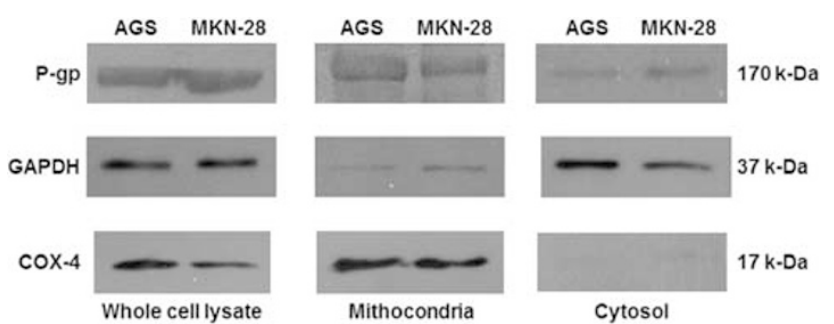

Figure 6 Western blot analyses of P-gp in whole cell lysate, mitochondrial and cytosolic fractions isolated from AGS and MKN-28 cells. Figure representative of three separate experiments. Each experiment was performed in triplicate. Note the substantial amount of P-gp in the mitochondrial fraction. membranous organelles, where it colocalized with $\mathrm{Bcl}-\mathrm{x}_{\mathrm{L}}$ (Figure 5). By staining the cells with both anti-Pgp antibody and MitoTracker Red, a specific mitochondrial dye, a significant fraction of P-gp was found localized at level of the mitochondria (Figure 5).

\section{Expression of $P$-gp in the mitochondrial fraction}

To confirm the presence of P-gp on the mitochondria, we fractionated total cell lysates of AGS and MKN-28 cells and isolated the mitochondrial fraction. As shown in Figure 6, the mitochondrial fraction contains a substantial amount of P-gp.

\section{Immunoprecipitation and immunoblot analysis}

Immunoprecipitation of total proteins extracted from AGS and MKN-28 cells with anti-P-gp or anti-Bcl- $\mathrm{x}_{\mathrm{L}}$ antibodies showed the presence of Pg-p in Bcl- $\mathrm{x}_{\mathrm{L}}$ immunocomplexes, as well as the presence of $\mathrm{Bcl}-\mathrm{x}_{\mathrm{L}}$ in P-gp immunocomplexes (Figure 7, panel a). Western blot on whole cell lysates con- a<smiles>[BH3-]</smiles>
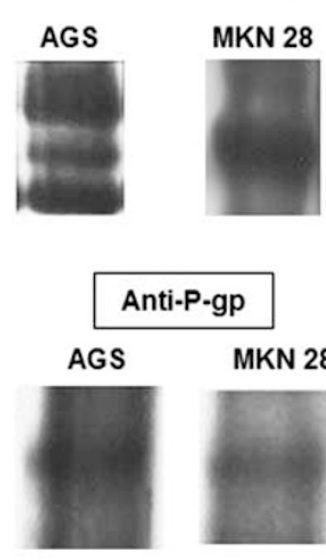

c
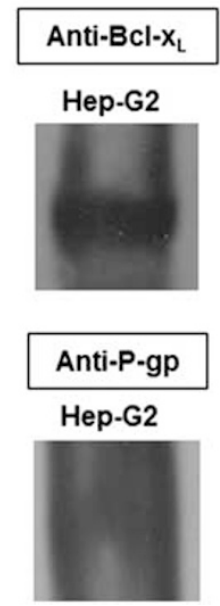

b

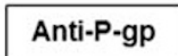

AGS

MKN 28
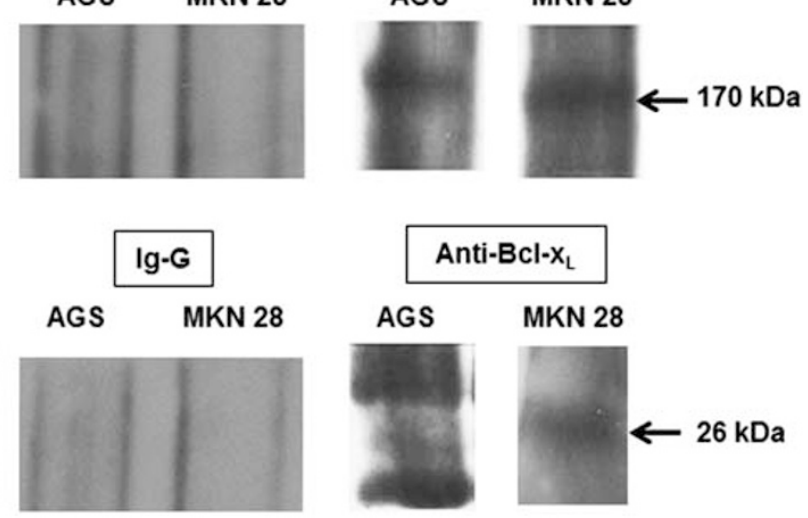

d
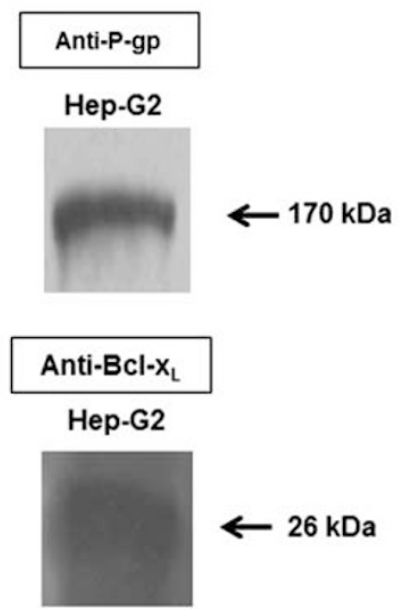

Figure 7 Immunoprecipitation of P-gp and Bcl $\mathrm{x}_{\mathrm{L}}$. The figure shows the interaction between P-gp and Bcl- $\mathrm{x}_{\mathrm{L}}$ proteins in human GC cell lines, AGS and MKN28, (panels $\mathbf{a}, \mathbf{b}$ ) and hepatocellular carcinoma (Hep-G2) cell line (panels $\mathbf{c}$, d). Extracts derived from AGS, MKN-28 and Hep-G2 cells were subjected to immunoprecipitation with Bcl- $x_{\mathrm{L}}$ or P-gp antibody. The immunoprecipitates (panels $\mathbf{a}, \mathbf{c}$ ) and whole cell lysates (panels $\mathbf{b}$, d) were resolved on an $10 \%$ SDSPAGE and immunoblotted with anti-Pgp or anti- BCl- $\mathrm{x}_{\mathrm{L}}$ antibody. Negative controls were obtained by using nonspecific mouse lgG. The experiments were performed in triplicate. 


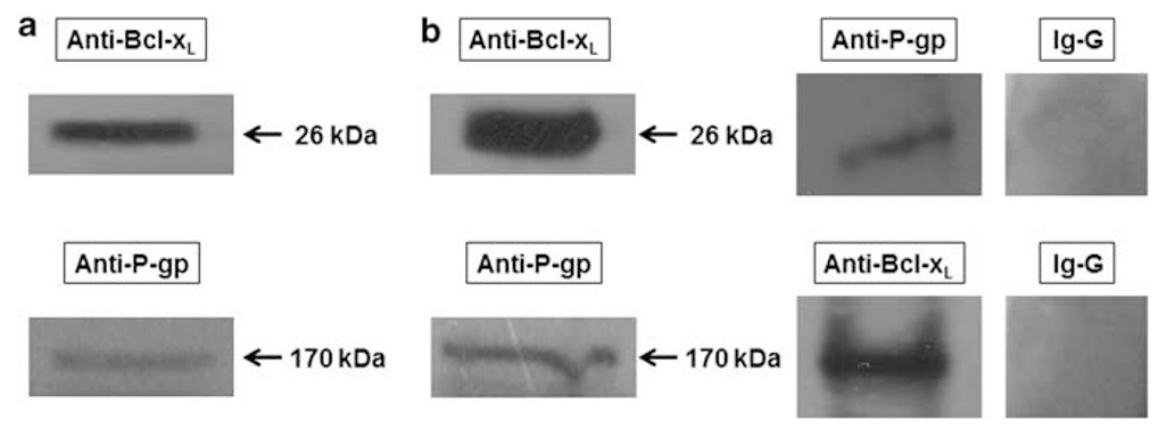

Figure 8 Immunoprecipitation of $\mathrm{P}$-gp and $\mathrm{BCl} \mathrm{X}_{\mathrm{L}}$ in AGS cell lines after stress-induced P-gp overexpression. The figure shows the basal expression of $\mathrm{P}$-gp and $\mathrm{Bcl}-\mathrm{x}_{\mathrm{L}}$ protein in AGS cells (panel a). Panel b shows the interaction between P-gp, overexpressed after $\mathrm{H}_{2} \mathrm{O}_{2}$-induced stress, and $\mathrm{Bcl}-\mathrm{x}_{\mathrm{L}}$. Note the increased interaction between the proteins.

Table 1 Mean percentage of necrotic, apoptotic and viable AGS and MKN-28 cells baseline and after $\mathrm{H}_{2} \mathrm{O}_{2}$-induced stress before and after knock-down of P-gp by siRNA

\begin{tabular}{|c|c|c|c|c|c|}
\hline Basal & Basal $+\mathrm{H}_{2} \mathrm{O}_{2}$ & Scramble & Scramble $+\mathrm{H}_{2} \mathrm{O}_{2}$ & Silenced & Silenced $+\mathrm{H}_{2} \mathrm{O}_{2}$ \\
\hline Mean $\% \pm$ s.d. & Mean $\% \pm$ s.d. & Mean $\% \pm$ s.d. & Mean $\% \pm$ s.d. & Mean $\% \pm$ s.d. & Mean $\% \pm$ s.d. \\
\hline
\end{tabular}

\section{AGS}

Necrosis

Apotosis

$2.3 \pm 0.2$

$6.4 \pm 0.5$

Viable

$88.3 \pm 0.8$
$14.5 \pm 0.7$

$22.6 \pm 0.6$

$62.9 \pm 1.1$

\begin{abstract}
$2.6 \pm 0.4$
$10.1 \pm 0.4$
\end{abstract}

$87.3 \pm 0.8$

\begin{abstract}
$15.2 \pm 0.6$
$23.1 \pm 0.5$
\end{abstract}

$61.7 \pm 0.5$
$13.6 \pm 0.8$
$9.4 \pm 0.5$

$80 \pm 0.9$
$7.9 \pm 0.3$

$90.3 \pm 1.2$

$1.8 \pm 0.4$

MKN-28

\begin{tabular}{|c|c|c|c|c|c|c|}
\hline Necrosis & $9.2 \pm 0.9$ & $21.7 \pm 1.3$ & $8.5 \pm 0.3$ & $23 \pm 0.9$ & $14 \pm 1.5$ & $11 \pm 0.3$ \\
\hline Apotosis & $3.3 \pm 0.6$ & $7.3 \pm 0.9$ & $3.6 \pm 0.2$ & $7.6 \pm 0.7$ & $9.8 \pm 0.4$ & $56.2 \pm 1.1$ \\
\hline Viable & $87.5 \pm 0.8$ & $71 \pm 0.8$ & $87.9 \pm 1.9$ & $69.4 \pm 0.8$ & $76.2 \pm 1.1$ & $32.9 \pm 1.0$ \\
\hline
\end{tabular}

firmed the expression of $\mathrm{P}-\mathrm{gp}$ and $\mathrm{Bcl}-\mathrm{x}_{\mathrm{L}}$ in $\mathrm{GC}$ cell lines (Figure 7, panel b). These data indicate the physical interaction of the two proteins in both GC cell lines. The interaction between P-gp and Bcl-xL was confirmed by immunoprecipitation and immunoblot also in Hep-G2 cell lysates (Figure 7, panels c and d). Stress-induced P-gp overexpression in AGS cell line resulted in an increased interaction between the two proteins (Figure 8).

\section{Inhibition of MDR1 expression by siRNA increases cell susceptibility to pro-apoptotic stimuli}

To test the role of P-gp in the control of apoptosis, we performed experiments of stress-induced apoptosis in AGS and $\mathrm{MKN}-28$ cell lines in which the expression of P-gp was downregulated by transfection with specific siRNA targeting P-gp. The expression of mitochondrial P-gp was abolished by MDR1-targeted siRNA in both cell lines (Figure 9). This effect was specific, because nonspecific control or scrambled siRNAs did not affect P-gp levels.

Cells, in which P-gp expression was knocked down, were subjected to oxidative stress by hydrogen peroxide and the fraction of apoptotic, necrotic or viable cells was measured by FACS analysis. The selective silencing of P-gp by siRNA results in a significant rise of the apoptotic index in both GC cell lines exposed to oxidative stress (AGS: from $22.6 \pm 0.6$ to $90.3 \pm 1.2 \% ; P<0.0001$ and $\mathrm{MKN}-28$ : from $7.3 \pm 0.9$ to $56.2 \pm 1.1 \% ; P<0.0001$ ) (Table 1 and Figure 9).

\section{DISCUSSION}

In this study, we found that P-gp is expressed in the fetal gastric mucosa, undetectable in adult normal gastric mucosa and re-expressed in a subset of $\mathrm{Hp}$-related CG and in GC, thus behaving as a gastric oncofetal protein. Tissue differentiation during development is largely under epigenetic control. Considerable experimental evidence indicates that epigenetic alteration, including DNA methylation, is important in tumor initiation and progression, as well as that reactivation of developmentally regulated genes may result from the aberrant hypomethylation observed in many tumor types. $^{24-26}$ In our study, the expression of P-gp in gastric mucosa seems to be dependent on the methylation status of its promoter, as typically reported for oncofetal proteins. 
a

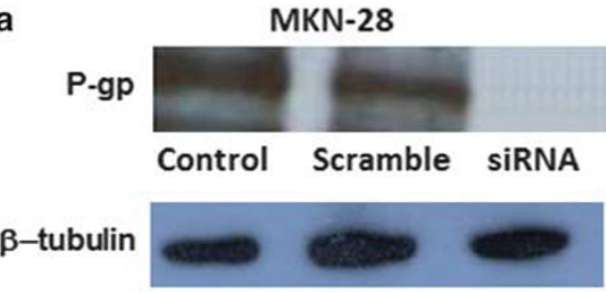

b

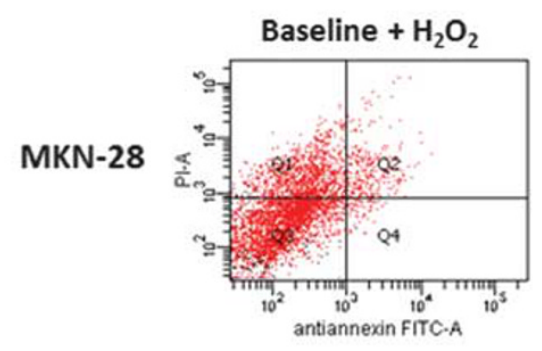

AGS

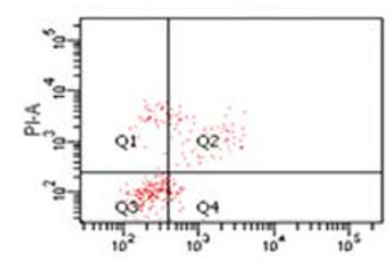

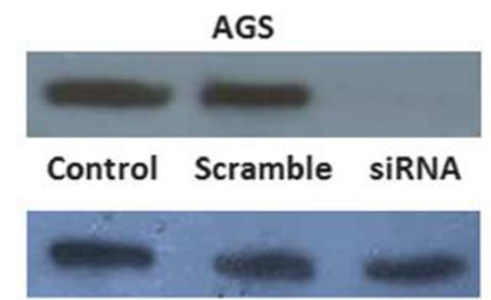
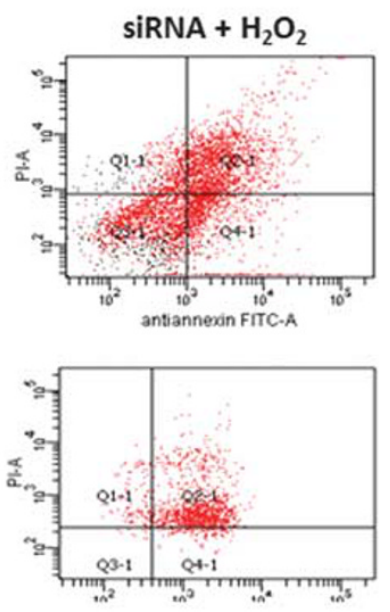

C

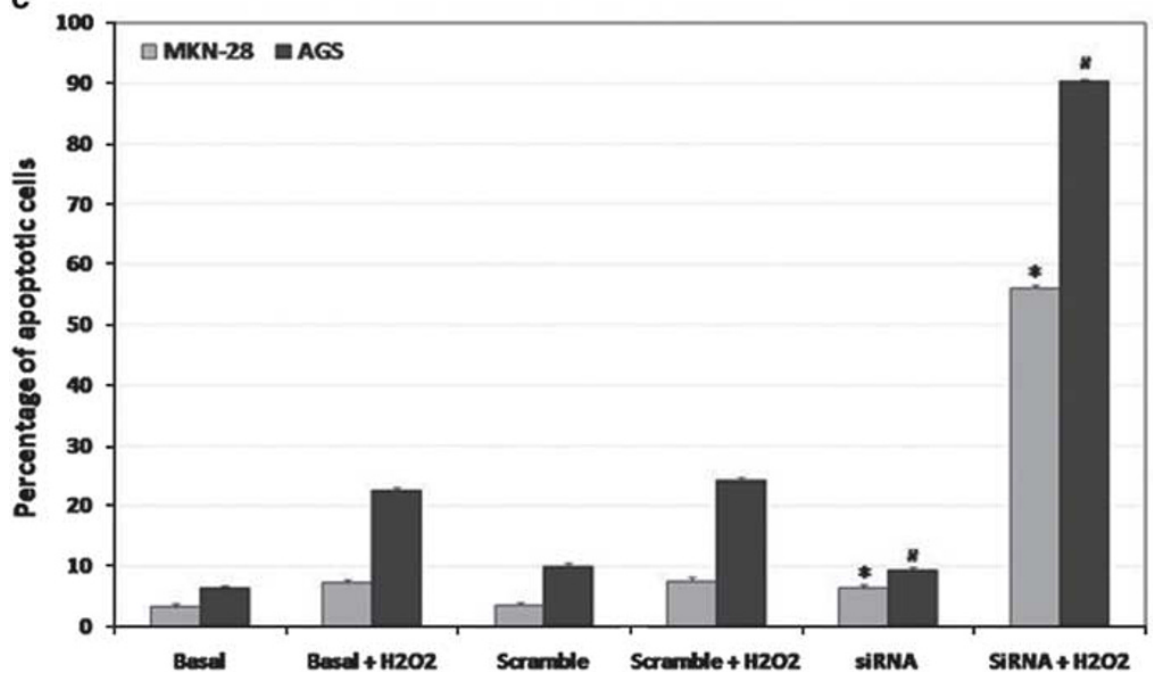

Figure 9 Transfection of siRNA against MDR1 and flow cytometry analysis. Selective knock down of P-gp amplifies stress-induced apoptosis in GC cell lines. MKN-28 and AGS cell lines were transfected with scrambled or P-gp-targeted siRNA. After $48 \mathrm{~h}$, the cell were collected and divided in two aliquots: the first was lysed and total extracts blotted with anti-P-gp antibodies (a). Another aliquot was exposed to $3 \% \mathrm{H}_{2} \mathrm{O}_{2}$ for $6 \mathrm{~h}$ and analyzed by FACS (b). The early apoptotic cells (Annexin-FITC positive and propidium iodide (PI) negative) were located in the lower right quadrant. The late apoptotic or necrotic cells (Annexin-FITC positive and PI positive) were located in the upper right quadrant. Healthy cells (negative for both probes) were located in the lower left quadrant. The results are expressed as percentage of positively stained cells in total cells. The panel $\mathbf{c}$ shows a quantitative representation of the targeting experiments. All experiments were performed in triplicate. ${ }^{\star} P<0.0001 ;{ }^{\#} P<0.0001$.

A positive relation has been reported between the expression of P-gp and survivin, a member of the inhibitors of apoptosis protein family, capable of blocking apoptosis through caspase-dependent or caspase-independent pathways. ${ }^{27}$ In our series of cases, the co-expression of P-gp and Bcl- $\mathrm{x}_{\mathrm{L}}$ suggests that, during stomach development, P-gp may have a physiological role, that is, to warrant survival of specific cellular populations, which characterizes the histological architecture and function of the mature organ. ${ }^{28,29}$ In contrast, in the adult, the co-expression of P-gp and Bcl- $\mathrm{x}_{\mathrm{L}}$, during $H p$-related gastric carcinogenesis, could result in prolonged survival of abnormal cells in which the sequential accumulation of molecular alterations can ultimately lead to tumor promotion and progression. $H p$ is the most important single factor responsible for inflammatory and neoplastic gastric diseases. ${ }^{30}$ The exposure of gastric epithelial cells to $H p$ results in a complex inflammatory reaction with the generation of reactive oxygen species and an 
increased level of nitric oxide synthase that exposes the cells to a significant oxidative stress. ${ }^{31}$ The cells with high levels of $\mathrm{P}$-gp and $\mathrm{Bcl}-\mathrm{x}_{\mathrm{L}}$ could escape stress-imposed death and accumulate DNA damage ultimately leading to cell transformation and cancer development. Opposite, the eradication of the Hp infection with the concomitant resolution of gastric inflammation may lead to the downregulation or even suppression of P-gp expression. In our study, indeed, after the successful eradication of $H p$ infection, P-gp was undetectable in all cases but persisted only in IM areas, where, it likely represents only an epiphenomenon of the 'intestinal phenotype'.

In support to the procarcinogenetic role of P-gp, it has been reported that a downregulation of the protein expression may be associated with reduced development of cancer. Kankesan et $a l^{32}$ reported that PSC833 (PSC), a potent inhibitor of P-gp, inhibited the development of $\mathrm{N}$-methyl- $\mathrm{N}$ nitrosourea-induced mammary cancer in female SpragueDawley rats and the growth of 1,2-dimethylhydrazineinduced liver cancer in rats. Mochida et $a l^{33}$ introducing disrupted alleles of the murine P-gp gene, $M D R 1 \mathrm{a}$, into Apc $(\mathrm{Min} /+)$ mice found that the number of polyps and cancers was markedly decreased in the MDR1a (-/-), Apc (Min/+) mutant mice, suggesting that P-gp has an active role during intestinal tumorigenesis. ${ }^{34}$

To elucidate the mechanisms through which P-gp elicits its anti-apoptotic function, we set an in vitro system, by using two GC cell lines, AGS and MKN-28, well and poorly differentiated, respectively. By means of immunofluorescence confocal microscopy, we found that P-gp and $\mathrm{Bcl}-\mathrm{x}_{\mathrm{L}}$ colocalized at the mitochondria level in both cell lines. The mitochondrial localization of P-gp has been previously shown in human hepatocarcinoma, hepatoma, breast cancer and myeloid leukemia cell lines. ${ }^{35-38}$ Mitochondria are the site where converge many of the factors, including members of Bcl-2 family, which elicit apoptosis. ${ }^{39}$ This subcellular distribution suggests that P-gp may participate in the regulation of apoptosis presumably via the mitochondrial pathway. In this study, by co-immunoprecipitation experiments, for the first time we demonstrated that in GC cell lines, P-gp physically interacts with $\mathrm{Bcl}-\mathrm{x}_{\mathrm{L}}$. Interestingly, the interaction between the two proteins was even more marked after stressinduced P-gp overexpression. These new findings further support the hypothesis that P-gp may have a fundamental role in controlling apoptosis. The occurrence of $\mathrm{P}-\mathrm{gp}-\mathrm{Bcl}-\mathrm{x}_{\mathrm{L}}$ interaction also in hepatocarcinoma cell line Hep-G2 indicates that this new relationship in not distinctive of GC. Finally, the selective silencing of P-gp by siRNA resulted in a significant rise of the cell apoptotic index in both GC cell lines exposed to oxidative stress, thus confirming the implication of P-gp in controlling apoptosis.

In conclusion, P-gp behaves as a gastric oncofetal protein that by acting as anti-apoptotic agent, confers a strong survival advantage to GC cells by cross-talking with $\mathrm{Bcl}-\mathrm{x}_{\mathrm{L}}$. The expression of P-gp in pre-neoplastic gastric mucosa could indicate a functional implication of this protein since the early phases of $H p$-related gastric carcinogenesis and might represent a useful biomarker to select patients at major risk of a progressive gastric disease.

\section{ACKNOWLEDGEMENTS}

This research was supported by grants from the Italian Ministry of University and Research (MURST) to the Department of Clinical and Experimental Medicine, Gastroenterology Unit, 'Federico II' University of Naples. We are grateful to Enrico Vittorio Avvedimento for helpful comments on the manuscript.

\section{DISCLOSURE/CONFLICT OF INTEREST}

The authors declare no conflict of interest.

1. Li $\mathrm{Y}$, Yuan $\mathrm{H}$, Yang $\mathrm{K}$, et al. The structure and functions of P-glycoprotein. Curr Med Chem 2010;17:786-800.

2. Mizutani T, Masuda M, Nakai $E$, et al. Genuine functions of P-glycoprotein (ABCB1). Curr Drug Metab 2008;9:167-174.

3. Goda K, Bacsó Z, Szabó G. Multidrug resistance through the spectacle of P-glycoprotein. Curr Cancer Drug Targets 2009;9:281-297.

4. Wang $\mathrm{B}$, Li XQ, Ma X, et al. Immunohistochemical expression and clinical significance of $\mathrm{P}$-glycoprotein in previously untreated extranodal NK/T-cell lymphoma, nasal type. Am J Hematol 2008;83: 795-799.

5. Mouly S, Paine MF. P-glycoprotein increases from proximal to distal regions of human small intestine. Pharm Res 2003;20:1595-1599.

6. Zhang $D$, Fan D. Multidrug resistance in gastric cancer: recent research advances and ongoing therapeutic challenges. Expert Rev Anticancer Ther 2007;7:1369-1378.

7. $\mathrm{Xu} \mathrm{HW}, \mathrm{Xu} \mathrm{L}, \mathrm{Hao} \mathrm{JH}$, et al. Expression of P-glycoprotein and multidrug resistance-associated protein is associated with multidrug resistance in gastric cancer. J Int Med Res 2010;38:34-42.

8. Nardone $G$, Rocco A, Vaira $D$, et al. Expression of COX-2, mPGEsynthase1, MDR-1 (P-gp), and Bcl-xL: a molecular pathway of $\mathrm{H}$ pylorirelated gastric carcinogenesis. J Pathol 2004;202:305-312.

9. Chipuk JE, Fisher JC, Dillon CP, et al. Mechanism of apoptosis induction by inhibition of the anti-apoptotic BCL-2 proteins. Proc Natl Acad Sci USA 2008;105:20327-20332.

10. Tainton KM, Smyth MJ, Jackson JT, et al. Mutational analysis of P-glycoprotein: suppression of caspase activation in the absence of ATP-dependent drug efflux. Cell Death Differ 2004;11: 1028-1037.

11. Mantovani I, Cappellini A, Tazzari PL, et al. Caspase-dependent cleavage of $170-\mathrm{kDa}$ Pglycoprotein during apoptosis of human T-lymphoblastoid CEM cells. J Cell Physiol 2006;207:836-844.

12. Guenova ML, Balatzenko GN, Nikolova VR, et al. An anti-apoptotic pattern correlates with multidrug resistance in acute myeloidleukemia patients: a comparative study of active caspase-3, cleaved PARPs, Bcl-2, Survivin and MDR1 gene. Hematology 2010;15:135-143.

13. Takanishi K, Miyazaki M, Ohtsuka M, et al. Inverse relationship between P-glycoprotein expression and its proliferative activity in hepatocellular carcinoma. Oncology 1997;54:231-237.

14. Potocnik U, Glavac D, Dean M. Common germline MDR1/ABCB1 functional polymorphisms and haplotypes modify susceptibility to colorectal cancers with high microsatellite instability. Cancer Genet Cytogenet 2008;183:28-34.

15. Van Brussel JP, Jan Van Steenbrugge G, Van Krimpen $C$, et al. Expression of multidrug resistance-related proteins and proliferative activity is increased in advanced clinical prostate cancer. J Urol 2001; 165:130-135

16. Hanahan D, Weinberg RA. The hallmarks of cancer. Cell 2000;100: 57-70.

17. Danial NN, Korsmeyer SJ. Cell death: critical control points. Cell 2004;116:205-219.

18. Dixon MF, Genta RM, Yardley JH, et al. Classification and grading of gastritis. Am J Surg Pathol 1996;20:1161-1181.

19. Jass JR, Filipe MI. The mucin profiles of normal gastric mucosa, intestinal metaplasia and its variants and gastric carcinoma. Histochem J 1981;13:931-939. 
20. Lauren P. The two histological main types of gastric carcinoma: diffuse and so-called intestinal type carcinoma. Acta Path Microbiol Scand 1965;64:31-49.

21. Ottini L, Falchetti M, Saieva $C$, et al. MRE11 expression is impaired in gastric cancer with microsatellite instability. Carcinogenesis 2004;25:2337-2343.

22. Garcia-Manero G, Daniel J, Smith TL, et al. DNA methylation of multiple promoter associated CpG islands in adult acute lymphocytic leukemia. Clin Cancer Res 2002;8:2217-2224.

23. van Rijnsoever M, Grieu F, Elsaleh $\mathrm{H}$, et al. Characterization of colorectal cancers showing hypermethylation at multiple CpG islands. Gut 2002;51:797-802.

24. Hu M, Shivdasani RA. Overlapping gene expression in fetal mouse intestine development and human colorectal cancer. Cancer Res 2005;65:8715-8722.

25. Lum L, Beachy PA. The Hedgehog response network: sensors, switches, and routers. Science 2004;304:1755-1759.

26. Vogelstein B, Kinzler KW. Cancer genes and the pathways they control. Nat Med 2004;10:789-799.

27. Liu F, Liu S, He S, et al. Survivin transcription is associated with $\mathrm{P}$ glycoprotein/MDR1 overexpression in the multidrug resistance of MCF-7 breast cancer cells. Oncol Rep 2010;23:1469-1475.

28. van Kalken CK, Giaccone $G$, van der Valk $P$, et al. Multidrug resistance gene (P-glycoprotein) expression in the human fetus. Am J Pathol 1992;141:1063-1072.

29. Ménard D, Arsenault P. Cell proliferation in developing human stomach. Anat Embryol (Berl) 1990;182:509-516.

30. The EUROGAST Study Group. An international association between Helicobacter pylori infection and gastric cancer. Lancet 1993;341: 1359-1362.
31. Nardone G, Rocco A, Malfertheiner P. Review article: helicobacter pylori and molecular events in precancerous gastric lesions. Aliment Pharmacol Ther 2004;20:261-270.

32. Kankesan J, Vanama R, Yusuf A, et al. Effect of PSC 833, an inhibitor of P-glycoprotein on Nmethyl-N-nitrosourea induced mammary carcinogenesis in rats. Carcinogenesis 2004;25: 425-430.

33. Kankesan J, Yusuf A, Laconi E, et al. Effect of PSC 833, an inhibitor of Pglycoprotein, on 1,2- dimethylhydrazine-induced liver carcinogenesis in rats. Carcinogenesis 2003;24:1977-1984.

34. Mochida Y, Taguchi K, Taniguchi S, et al. The role of P-glycoprotein in intestinal tumorigenesis: disruption of mdr1a suppresses polyp formation in $\mathrm{Apc}(\mathrm{Min} /+)$ mice. Carcinogenesis 2003;24: 1219-1224.

35. Solazzo $M$, Fantappiè $\mathrm{O}$, Lasagna $\mathrm{N}$, et al. P-g localization in mitochondria and its functional characterization in multiple drugresistant cell lines. Exp Cell Res 2006;312:4070-4078.

36. Shen $Y, C h u, Y, Y a n g ~ Y$, et al. Mitochondrial localization of P-glycoprotein in the human breast cancer cell line MCF-7/ ADM and its functional characterization. Oncol Rep 2012;27: 1535-1540.

37. Ling $X, \mathrm{He} Y$, Zhang $\mathrm{G}$, et al. Increased P-glycoprotein expression in mitochondria is related to acquired multidrug resistance in human hepatoma cells depleted of mitochondrial DNA. Int J Oncol 2012:40:109-118.

38. Munteanu E, Verdier M, Grandjean-Forestier F, et al. Mitochondrial localization and activity of P-glycoprotein in doxorubicin-re sistant K562 cells. Biochem Pharmacol 2006;71:1162-1174.

39. Green DR, Kroemer G. The pathophysiology of mitochondrial cell death. Science 2004;305:626-629. 